JHR

32,2

Received 1 July 2017 Accepted 1 September 2017

\title{
The experiences of survivors of intimate partner violence in Thai women
}

\author{
Suwannee Sroisong and Somporn Kantharadussadee Triamchaisri \\ Department of Public Health Nursing, Faculty of Public Health, \\ Mahidol University, Bangkok, Thailand \\ Ronnachai Kongsakon \\ Department of Psychiatry, Faculty of Medicine, Ramathibodi Hospital, \\ Mahidol University, Bangkok, Thailand \\ Trude Bennett \\ Department of Maternal and Child Health, Gillings School of Global Public Health, \\ The University of North Carolina at Chapel Hill, Durham, North Carolina, USA, and \\ Ratchneewan Ross \\ School of Nursing, The University of North Carolina at Greenboro,
North Carolina, USA
}

\begin{abstract}
Purpose - The study on experiences of women with intimate partner violence (IPV) reveals the meanings of recovering psychological health and independence from their abuser. However, not much study has been done to reveal experiences of abused women in their attempt to recover from their past traumatic experiences in the context of Thai society. The purpose of this paper is to explore experiences of survivors of IPV in Thai women.

Design/methodology/approach - Key informants included ten women who had experienced IPV and left abusive relationships. They were recruited from a provincial hospital in upper southern part of Thailand. Data were collected from in-depth interviews and analyzed using a phenomenological method.

Findings - Findings showed that five themes had emerged as follows: seeking help and support; decision to terminate the abusive trap; enhancing empowerment to solve their problems; learning to forgive the abuser; and adopting the ability to stand on one's own two feet.

Originality/value - The study helps shed light on the recovering of the abused women. The survivors had faced psychological suffering and economic problems. Therefore, they need supports in order to make the exit possible and to use group support to increase their strength in fighting against an abusive relationship.
\end{abstract}

Keywords Intimate partner violence, Survivor, Phenomenological method

Paper type Research paper

\section{Introduction}

Intimate partner violence (IPV) today remains both a public health problem and a hidden social problem that significantly threatens women's physical and mental health around the

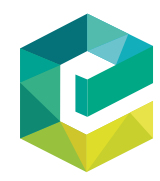
globe[1-3]. In Thailand, data from Women's Affairs and Family Development revealed that

(c) Suwannee Sroisong, Somporn Kantharadussadee Triamchaisri, Ronnachai Kongsakon, Trude Bennett and Ratchneewan Ross. Published in the Journal of Health Research. Published by Emerald Publishing Limited. This article is published under the Creative Commons Attribution (CC BY 4.0) licence. Anyone may reproduce, distribute, translate and create derivative works of this article (for both commercial \& non-commercial purposes), subject to full attribution to the original publication and authors. The full

This paper is a part of doctoral dissertation of Public Health Nursing, Faculty of Public Health, Mahidol University, Thailand. 
the number of women and children suffering from domestic violence significantly increased yearly between 2010 and 2013 from 25,767 to 31,866 persons, 87 women and children being abused per day on an average. More than 85 percent of the violence was perpetrated by men, with approximately 70 percent caused by a spouse or intimate partner[1,3]. In addition, some married Thai women have been physically abused by their partners more than twice during their coexistence[3, 4$]$.

IPV is considered both an individual and a family matter in the Thai culture[3]. Incidences of violence taking place in families are often not reported. Thus, the statistics on violence are likely to be underestimated. Studies of intimate violence against Thai women have found a range of coping mechanisms: electing to remain patient and stay with the perpetrator, feeling inferior, ending the abusive relationship or even killing the abuser[3-5]. In a study of coping methods of abused women, Tanopas found that, while many tried to maintain their status in an abusive relationship or manage their suffering by seeking help, some committed suicide as a means of ending the abusive relationship[5].

The consequences of IPV include deleterious physical, emotional, psychological and economic effects to victims[1, 6-8]. Overcoming IPV is a challenge for abused women. A number of investigators in western countries have found that victims often attempt to leave or end abusive relationships, including seeking help from social support or a police response, only when their health or overall situation becomes severe[7, 9]. Still, although western research has revealed data on the recovering experience of IPV survivors, little is known about the adaptation methods of abused Thai females to survive and overcome IPV. This research study presented experiences of women survivors of IPV with the qualitative method, the purpose to explore experiences of survivors of IPV in Thai women. This understanding would be useful to further improve the health service care side for women survivors of IPV in the future.

\section{Methods}

A phenomenology methodology was employed to describe the experiences and perspectives as shared in their own words of survivors of IPV among Thai women via in-depth interviews. This study was approved research ethics by the Committee of Mahidol University's Human Subjects Review Board, Mahidol University, Thailand.

\section{Key informants}

Key informants were ten abused women who had left abusive relationships and had been able to articulate their experiences in an interview which took place in a provincial hospital in upper southern part of Thailand. At the time of the study, the women were ending their relationships with their abusers. The women were recruited by two gatekeepers who were working at this hospital.

\section{Instruments}

This study employed the interview guideline on the experience of survivors with IPV. The interview guideline contains questions about IPV experiences and perspectives relating to living with abusers, overcoming abusive relationship, help and support to dealing with the IPV, etc. The guideline developed by the researcher was checked by three experts for content validity and were corrected accordingly.

\section{Procedure}

After receiving the approval from the Ethics Committee, the researcher contacted two gatekeepers. One of the gatekeepers was a counseling nurse and the other was a 
JHR

32,2

134

social worker. At the first meeting, the researcher explained the study's purpose, gave some study details, obtained verbal consent and arranged a place for an interview which was convenient for the woman. Participants were informed by both written and oral means as to the purpose and nature of the research prior to signing consent. Moreover, the participants were informed that they could withdraw their consent at any time during the study. In the interview, the researcher asked each individual to respond to the following questions: could you describe your experience of living with spouses/partner abusers? Could you describe your experience of going through a violent situation? What helped you to overcome the violence? How did you feel after overcoming the violence problem? Each question invited the participant to expand on and provide a wide range of descriptions or perceptions of her own resilience. At the end of each interview, the participant was asked whether there was anything else that she would like to add. The researcher made follow-up appointments with the participants at least twice at their home or when they joined their group support at the hospital. These went on until saturation of information was achieved and all insights into the phenomenon were disclosed. All interviews were tape-recorded with the permission of the participants. The interviews which lasted 60-120 minutes took place once a month. Each participant was identified by a pseudonym to maintain anonymity.

\section{Data analysis}

Data were analyzed using the phenomenological method. Analysis comprised seven steps as follows: the researcher repeatedly listened to and transcribed the audio tapes, rereading the transcripts multiple times to make sense of the whole account; significant statements were extracted by labeling phrases or sentences using a line by line approach; similar phenomena and meanings from these significant statements were formulated; formulated meanings were categorized into clusters of themes; findings were integrated into exhaustive descriptions of the phenomena; results were validated by taking the findings to some participants to compare their experiences with the researcher's description; and any changes to descriptions following the participants' offerings were included in the essence of the phenomena in questions[10].

When data are analyzed, it is important that the both data and interpretation meet the test of trustworthiness. In a qualitative inquiry, this involves four categories: credibility, transferability, dependability and confirmability[11]. To increase credibility, transcripts were taken back to participants for data verification. Additionally, the researcher created rapport with participants by involving them in a support group to share their experiences and by visiting the homes of the participants to ensure transferability. To attain dependability and confirmability, the analysis process was reviewed by the thesis advisors.

\section{Results}

Characteristics of the participants presented in Table I. The age of participants ranged from 29 to 52 years. Half of them just left their husband while the other half got their divorce properly. Some of them had only primary education (three persons). Others had secondary (six persons). Only one had a Bachelor degree. Three received psychological, physical and economic deprivation. Two received psychological, physical, sexual, economic and social problems. Two suffered psychological, physical, sexual, and economic burden. One suffered psychological, physical and economic burden. One suffered psychological, physical, economic and social problems. One suffered psychological, sexual and economic problems. The duration of the violence lasted from 3 to 15 years. Nine of the women had children. 


\begin{tabular}{|c|c|c|c|c|c|c|c|c|c|c|c|c|}
\hline $\mathrm{P}$ & Age (yrs) & Status & $\begin{array}{l}\text { Edu } \\
\text { (yrs) }\end{array}$ & Occupation & Psycho & $\begin{array}{r}\text { Type } \\
\text { Physical }\end{array}$ & $\begin{array}{l}\text { of violen } \\
\text { Sexual }\end{array}$ & Eco & $\begin{array}{c}\text { Social } \\
\text { isolation }\end{array}$ & $\begin{array}{c}\text { Duration of } \\
\text { violence (yrs) }\end{array}$ & $\begin{array}{l}\text { No of } \\
\text { Child }\end{array}$ & IPV \\
\hline 01 & 29 & Separated & 12 & Farmer & $\mathrm{Y}$ & $\mathrm{Y}$ & - & $\mathrm{Y}$ & - & 5 & 2 & \\
\hline 02 & 43 & Separated & 6 & Employee & $\mathrm{Y}$ & $\mathrm{Y}$ & $\mathrm{Y}$ & $\mathrm{Y}$ & $\mathrm{Y}$ & 5 & 3 & \\
\hline 03 & 43 & Separated & 4 & Employee & $\mathrm{Y}$ & $\mathrm{Y}$ & $\mathrm{Y}$ & $\mathrm{Y}$ & - & 5 & 2 & \\
\hline 04 & 50 & Divorced & 12 & Farmer & $\mathrm{Y}$ & $\mathrm{Y}$ & $\mathrm{Y}$ & $\mathrm{Y}$ & - & 15 & 2 & 12 \\
\hline 05 & 44 & Divorced & 12 & Farmer & $\mathrm{Y}$ & $\mathrm{Y}$ & - & $\mathrm{Y}$ & - & 13 & 2 & 13 \\
\hline 06 & 39 & Divorced & 12 & Merchant & $\mathrm{Y}$ & $\mathrm{Y}$ & $\mathrm{Y}$ & $\mathrm{Y}$ & $\mathrm{Y}$ & 13 & 2 & \\
\hline 07 & 36 & Separated & 14 & Merchant & $\mathrm{Y}$ & $\mathrm{Y}$ & - & $\mathrm{Y}$ & $\mathrm{Y}$ & 12 & 2 & \\
\hline 08 & 48 & Separated & 14 & Officer & Y & - & Y & $\mathrm{Y}$ & - & 4 & - & \\
\hline 09 & 37 & Divorced & 18 & officer & $\mathrm{Y}$ & $\mathrm{Y}$ & - & $\mathrm{Y}$ & - & 3 & 1 & \\
\hline 10 & 52 & Divorced & 7 & Employee & Y & Y & - & $\mathrm{Y}$ & - & 4 & 2 & \\
\hline & Separated $=5$ & & & & 10 & 9 & 5 & 10 & 3 & Range & Range & Table I. \\
\hline & Divorced $=5$ & & & & & & & & & $3-15$ & $1-3$ & Characteristics of the \\
\hline \multicolumn{12}{|c|}{ Notes: $n=10 . P$, participant; Edu, education; Eco, economic deprivation; $\mathrm{Y}$, yes } & participants \\
\hline
\end{tabular}

All survivors with IPV have ended their married status and have occupation. All of them are similar profiles. Moreover, data of abuses related to factors influenced IPV such as patriarchy, have an affair, drunk, drug addict and gambling.

Interviews were conducted with these survivors. Five major themes showed the experience of survivors with IPV. These themes are presented below with excerpts from interviews to illustrate the themes: seeking help and support; making the decision to terminate the abusive trap; enhancing empowerment and social support; learning to forgive the abusers; and gaining the ability to stand on one's own two feet.

\section{Seeking help and support}

Seeking support is important to help survivors escape the abusive cycle. Survivors cannot face or deal with violence alone because the abuser performed aggressive and coercive behaviors toward his wife. In addition, he repeatedly assaulted his partner. Thus, survivors will typically seek help from their siblings or parents or flee severe violent circumstances. Moreover, they need to seek support to lessen the impact of their abusers. Survivors got several kinds of help from both informal and formal sources that can provide safety:

My marriage was not happy. He had sexual relationships with my friend at our house. He also brought her to live with us. He always quarreled and hit me and locked me up in a dark room when he abused me. He repeatedly assaulted me although he would tell me that he loved me. I was so upset and could not tolerate it. Finally, I decided to escape from him in order to live with my parents. My mom supported me and also gave me some money and many other things (Participant 02,43 years old).

Sometimes he acted madly and always hit me. He has AIDS from sleeping with a prostitute. He forced me to have sex with him daily. I asked him to use a condom and sometimes he used it. I also got pain on intercourse and asked him to stop. Fortunately, I don't have AIDS, but I felt distressed and cried all the time. I could not sleep at night. I asked my older brother and sister to help me. My brother took me to his house in another town. Then I came to stay at the Emergency House in my hometown so that I could get help and could file a petition for divorce (Participant 06,39 years old).

He often said I was bad. The worst was that, he was quite insane. He tried to use a knife to slash me. He threatened to kill all at our home. My child and I were very afraid. We jumped out of the window to flee. We hid ourselves in the palm trees. We were very afraid and very hungry because we had not had dinner. We were frightened and slept there until early morning. 
And, I called a social worker to help us and went back to live with my mum (Participant 05, 44 years old).

When he drank, he repeatedly assaulted me. Sometimes he left me outside home all night. I felt pain and was afraid of him. Finally, I consulted my closed friend by a mobile phone. She helped me solve the problem and encouraged me to plan to leave my husband. I began to hide money and collected money to start a new life. Later, my friend found a new house for me to open an internet shop in another district (Participant 07, 36 years old).

\section{Decision to terminate the abusive trap}

When participants were repeatedly threatened, they struggled with the risk of not only physical and psychological harm, but also economic and financial difficulties. Moreover, the participants felt powerless to stop the violent and manipulative behaviors toward them. They felt instead the need to stay quiet and show patience. Survivors considered that if they still lived with their partners, they and their children would be exposed to the violence, which could lead to dire negative consequences. However, the participants eventually needed to change their way of purposive thinking in order to ensure the safety of themselves and of their children's lives. They ultimately decided to leave the violent relationship by fleeing, asking for help from parents, relatives or friends. In some cases, health providers were involved, and this is described in the following interviews:

He threatened to hurt me. He slapped, hit, and kicked me. Even at the time I was working, he also went and abused me there. He didn't allow me to work. Some days when I went to sell some stuff at the market, he followed me and abused me. I felt stressed and frightened. There was nothing good in my life. My children were exposed to the violence and both of them felt bad about their father. I'm anxious about risk behavior of children. They might become fierce and bad persons. I finally realized I couldn't put up with him any more, so I decided to leave him and moved to stay with my older brother and sister in Bangkok (Participant 06, 39 years old).

I was living with my boyfriend when I was 16 . It is a myth that a husband abuses the wife because of love. Before, I used to think that my husband abused me because he had his right to do so. A woman has to love her husband, whatever he does, so I had to surrender patiently. I was concerned about my children. Later, when I was taken to consult peers and social workers, I decided to leave him to stop the abuse (Participant 03, 43 years old).

Later, he threatened my child and me. We feared his coming back to assault us again. We did not go back to live with him. I got a new mobile phone. Moreover, I consulted a lawyer in order to help me divorce him decisively. After we divorced, he never harassed me anymore. Now I am free from him. If I am not free from him, I will always become a weak person (Participant 05, 39 years old).

He (the abuser) accused me of committing adultery and then hit me and locked me in a room where I was trapped inside for 2 days. I couldn't escape. The window was barred. I was frustrated and felt oppressed. I asked my daughter to give me a mobile phone and called the number 1300 to ask a social worker for help. The social worker and some policemen helped to unlock the room. He was angry at me so much. Then, I made the decision to terminate our married. I had only one backpack and I took a few clothes. He gave nothing. I had 500 baht (approximately $\$ 14$ ) in my pocket (Participant 04, 50 years old).

\section{Enhancing empowerment and social support}

A support group is crucial to find solutions, to increase inner strength and to leave the abusive cycle and survive beyond the abuse. In a support group, participants can share their stories of conflict, tension and problems related to their intimate violence circumstances. Critical understanding is obtained within the group. According to the participants, the group helped to enhance self-esteem and provided a social network and essential support. 
The women became courageous and able to speak openly about the violence. They gained an understanding of the proper way to end the violence or how to solve it through a process which included accepting the situation, improving their own thoughts and coping with the problem, particularly regarding emotional, in order to help them gain power and self-esteem and to develop coping skills. The participants said the following:

After I joined the support group, my friends shared their experiences and encouraged me to talk and change my thoughts. I have to be firm and not fearful because health providers and social workers helped and supported us. So, they looked for a job for me and I now work as a gardener in the hospital (Participant 03, 43 years old).

I joined a support group of women experiencing violence. My friends spoke about their situations. Their circumstances were more severe than mine. They told me humans have to love themselves first. If an abuser loved me, he would not abuse me. Later, I dared to speak about my story. The support groups helped me recover from disturbing thoughts and bolstered my ability to cope with the stress. I regained strength, and I began to understand the human rights. The social workers also suggested that I should confidentially speak about the violence with the police and the abuser (Participant 01, 29 years old).

I did not break down any more because I got emotional support and counseling support from the social workers and the newly formed network. Still, the effects of the violence gave me great pain in dealing with my abuser. Group support is crucial and essential to abused women. The peer and health provider team encouraged and supported me in the solving of my problem. I was not alone anymore. Then, I decided to find a new place to live to escape from this painful situation. After I recovered from my traumatic life, I discovered my inner strength. I made myself useful by using my experiences to help other abused women. I joined support groups. I told them what I had been through, and I helped train them how to deal with an abuser. Listening to other abused women help me to find a way out of this situation (Participant 04, 50 years old).

\section{Learning to forgive the abuser}

Forgiveness helps survivors reduce resentment and revenge. Methods that they used for retaliation against the abusers included making merits, praying and practicing mindful meditation. These are parts of the Buddhist religion and a basic function. Moreover, the pray included pouring of water to let go their past negative life. Furthermore, practicing mindfulness meditation helps them focus on the present moment. It can also heal the emotional wounds. Thus, they gradually got rid of negative feelings and past sufferings as well as enhanced inner strength. For instance, a participant said:

In the past, I felt very angry and wanted to revenge. I felt tense and unhappy all the time. I went to a temple to practice Dhamma. I always prayed in the early morning and evening. After praying, I poured water for him (the abuser). I gradually forgave what my partner had done to me and my suffering was overcome. I felt relief. Now, when I face a critical situation, I will breathe deeply, which is my techniques of relaxing, and I believe I have learned something from these situations in a positive way (Participant 03, 43 years old).

I practiced mindfulness and prayer to forgive what my partner had done to hurt me in the past. I had no more anger, nor did I want revenge. If I kept the bad experiences in my mind, the stress would drain my energy and ruin my life. So, I let it go, did not hold on to it, and tried to control my thoughts, thinking only of what my problems were and how to solve them (Participant 05, 44 years old).

If I still recalled the suffering in the past, I had an overwhelmed feeling. The negative feeling could hurt me and made my health worse. Anyway, I believed in the way of Buddhism. So I often made merit and poured water to him (the abuser). Sometimes, I prayed for better life. Now, I have less distress. I can gradually overcome a past conflict and suffering (Participant 07, 36 years old). 
Gaining the ability to stand on one's own two feet

Economic independence is the main thing for stability and survival in life. Participants were employed and they earned an income. Especially, they focused on work and children. It was a challenge to earn for themselves and their children. The more they work, the more money they earn. They hardly had time to think about the experience of violence. For instance:

After leaving him, I could help myself. I own a rubber farm. Apart from working on my own farm, I work as a labourer in many places and earn 8,000-9,000 extra baht a month. That was enough to support myself and my children. I felt comfort and happiness. I did not have anything more to deal with him (Participant 05, 44 years old).

I got a new job in a hospital. I was proud of myself. I was happier. I saved some money. I could buy what I wanted. I bought new clothes. My friend gave me a compliment that I looked more beautiful in my new clothes. My confidence returned (Participant 03, 43 years old).

I started a small internet café. I wanted to stand in my own shoes because I was inspired by an old man I saw on TV. He kept working and helping himself, even though he was nearly 90 years old. I felt I should work harder than him. I wanted to see my children have a good future. I felt still younger and healthier than when I stayed with him (Participant 07, 36 years old).

Earning a living was a key factor which made participants happy and which increased their feelings of self-worth and confidence for the participant. Moreover, they felt empowered to stand on their own feet.

\section{Discussion}

The findings made clear an understanding of how survivors dealt with IPV. Participants in this study sought help and terminated the abusive relationship to stop the violence. In particular, the IPV was help by parents and friends who took them to safe places, gave them emotional support and money in the same manner as in previous studies' findings. There is a great deal of support for the abused women who seek help from family and friends not only to cope alone emotionally with the abused, but also to protect themselves and their children. Women turn to their family and friends for advice, inspiration, and encouragement but also for tangible support (e.g. financial assistance, help with children, a place to stay) leading to greater psychological well-being and higher self-esteem[12-14]. However, some survivors who did not have siblings near at hand would seek help from service providers such as an OSCC officer and health volunteers. Some of them need to consult police and/or a lawyer to help process their divorce. The finding is congruent with Dichter and Gelles, which reported that abused women need both informal and formal support system to help protect them[15].

As for the survivors who have their children with them, their worries were greater because their children might also have been psychologically affected and might develop aggressiveness. Thus, the survivors decided to get away as soon as possible from the violent circumstances. Similarly, previous studies showed that violence against the mothers could lead to a range of deleterious outcomes and mental health problems in their children. Children are direct victims and may start to become abusers themselves against their future intimate partners which may last for more generations to come[16].

Women in abusive relationships were afraid, ashamed and powerless, and had low self-esteem. Their feeling of powerlessness may lapse into depression, anxiety and passivity. Support groups are some people who provided encouragement and the feeling that they are not alone. First, social workers and a health team provided professional counseling, deeply listening to their suffering and giving useful and necessary information. In addition, group support activities were given to these women to share their painful situations and give them 
emotional support. The health team invited them to participate in a group support of women who previously experienced the same IPV and who have been able to overcome their painful feelings. Later, these women gradually changed their way of thinking and built networks of members to help them solve the problems and increase their inner strength. In addition, they can consult police or lawyers about getting a divorce. These present findings are consistent with those of the previous study in that there are support groups to help abused women[17, 18]. This new situations are a challenge for them to abandon the previous unprofitable way of thinking and to find work and welcome the new way of free and safe living[19]. Moreover, support groups have helped these women to increase self-esteem because these supports have positive effects on their health[17, 20, 21].

In addition to forgiving the abuser, the survivors seemed to feel secure and relieved from all their previous unbearable suffering. Their retaliations against their abusers included making merits, praying and practicing mindfulness meditation to reduce resentment and revenge, consistent with the result of previous studies that forgiveness is important for a self-healing effect on survivors of IPV, is significant on alleviating feelings such as self-blaming and depression and is significant in promoting positive psychological adjustment in survivors[22, 23]. In particular, religious practice related to forgiveness can change emotional distress and can let go of anger, resentment and suffering[24, 25]. They also foster positive feelings, right thinking, self-love, self-worth and benevolence[26, 27]. Practicing mindfulness improves cognitive function and reduces stresses[28]. Similarly, the study of Goldsmith, Gerhart, Chesney, Burns, Klienman and Hood indicated that mindfulness-based stress reduced shame and depression among post-traumatic people[29]. Moreover, the praying and pouring of water is for letting negative things pass and encouraging the mind to feel better[28, 30]. Thus, survivors gradually got rid of negative feeling and past suffering. Additionally, they could overcome the violence and promote strength in the spiritual health.

Besides promoting health in daily life, another important thing is earning their living so that they are not a burden to their friends and families. They had to find a new job and do harder work to promote economic stability with an aim to raise their children in a safe environment. It is a good thing to help them go through the period of financial hardship. Thus, a health team is needed to help them find a new job. Moreover, these experiences gave them confidence and power. Similarly to the studies of Hetling, Stylianou and Postmus[8] and Kulkarni, Bell and Rhodes[17], findings indicated that IPV survivors needed access to work, access to job resources and self-efficacy to solve difficult problems. Consistent with previous research on recovery experience of Taiwanese women after terminating abusive relationship, there was a report that the survivors maintained a positive attitude and look forward to their future relationship during the recovery process[31]. Moreover, they rebuilt their self-value and life meaning[31].

\section{Conclusion}

It can be concluded from this study that, despite the fact that the survivors experienced IPV had faced sufferings, namely, physical, psychological and economic, they could cope with the problems by getting a variety of help such as help from the family, group support and health providers. As a result from these groups, they are able to increase self-esteem and feel ready to join a group support activity. Besides, all of them are able to end abusive relationship. Moreover, they had to release resentfulness and build positive strategic coping by practicing mindfulness. Group support is a way to enhance health policy implementation among related comprehensive stakeholders not only in government but also in private sectors. There should be practical guidelines and implementation programs of multidisciplinary action to achieve more effective implementation of the regulation. This study helps shed light on the method of overcoming and recovering of women with IPV. 


\section{References}

1. World Health Organization [WHO]. National report on violence health. Geneva: World Health Organization; 2005.

2. World Health Organization [WHO]. National report on violence and health Thailand. Kobe: WHO Kobe Centre; 2007.

3. The Women's Affairs and Family Development. Report on violence health. Bangkok: Thai Health Promotion Foundation (in Thai); 2013.

4. Archavanijakul K, Im-em W and Lertsrisuntut U. Impacts of intimate partner violence to women health. Nakhonpathom: Institute for Population and Social Research, Mahidol University. (in Thai); 2003.

5. Tanopas B. Development and psychometric testing of the abused wife coping scale. [Doctoral Dissertation]. Bangkok: Faculty of Graduate Studies, Mahidol University; 2005.

6. Dutton MA, Green BL, Kaltman SI, Roesch DM, Zeffiro TA, Krause ED. Intimate partner violence, PTSD, and adverse health outcomes. J Interpers Violence. 2006 Jul; 21(7): 955-68. doi: 10.1177/0886260506289178

7. Enander V. A fool to keep staying: battered women labeling themselves stupid as an expression of gendered shame. Violence Against Women. 2010 Jan; 16(1): 5-31. doi: 10.1177/1077801209353577

8. Hetling A, Stylianou AM, Postmus JL. Measuring financial strain in the lives of survivors of intimate partner violence. J Interpers Violence. 2015 Mar; 30(6): 1046-64. doi: 10.1177/ 0886260514539758

9. Flasch P, Murray CE, Crowe A. Overcoming abuse: a phenomenological investigation of the journey to recovery from past intimate partner violence. J Interpers Violence. 2015 Aug; 32(22): 3373-401. doi: 10.1177/0886260 515599161

10. Liamputtong P. Research methods in health foundations for evidence-based practice. Victoria: Oxford University Press; 2010.

11. Shenton AK. Strategies for ensuring trustworthiness in qualitative research projects. Education for Information. 2004; 22: 63-75.

12. Goodkind JR, Gillum TL, Bybee DI, Sullivan CM. The impact of family and friends' reactions on the well-being of women with abusive partners. Violence Against Women. 2003; 9(3): 347-73. doi: $10.1177 / 1077801202250083$

13. Leone JM, Johnson MP, Cohan CL. Victim help seeking: differences between intimate terrorism and situational couple violence. Fam Relat. 2007; 56(5): 427-39. doi: 10.1111/ j.1741-3729.2007.00471.x

14. Leone JM, Lape ME, Xu Y. Women's decisions to not seek formal help for partner violence: a comparison of intimate terrorism and situational couple violence. J Interpers Violence. 2014 Jul; 29(10): 1850-76. doi: 10.1177/0886260513511701

15. Dichter ME, Gelles RJ. Women's perceptions of safety and risk following police intervention for intimate partner violence. Violence Against Women. 2012 Jan; 18(1): 44-63. doi: 10.1177/ 1077801212437016

16. Eriksson L, Mazerolle P. A cycle of violence? Examining family-of-origin violence, attitudes, and intimate partner violence perpetration. J Interpers Violence. 2015 Mar; 30(6): 945-64. doi: $10.1177 / 0886260514539759$

17. Kulkarni SJ, Bell H, Rhodes DM. Back to basics: essential qualities of services for survivors of intimate partner violence. Violence Against Women. 2012 Jan; 18(1): 85-101. doi: 10.1177/ 1077801212437137

18. Tutty LM, Bidgood BA, Rothery MA. Support groups for battered women: research on their efficacy. J Fam Violence. 1993 Dec; 8(4): 325-43. doi: 10.1007/bf00978097

19. Postmus JL, Severson M, Berry M, Yoo JA. Women's experiences of violence and seeking help. Violence Against Women. 2009 Jul; 15(7): 852-68. doi: 10.1177/1077801209334445 
20. Mlinac ME, Sheeran TH, Blissmer B, Lees F, Martins D. Psychological resilience. In: Resick B, Gwyther LP, Roberto KA. (Eds), Resilience aging: concept, research, and outcomes. New York, NY: Springer; 2011; 67-87.

21. Schwarzer R and Leppin A. Social support and health: a theoretical and empirical overview. J Soc Pers Relat. 1991; 8(1): 99-127. doi: 10.1177/0265407591081005

22. Chang EC, Kahle ER, Yu EA, Hirsch JK. Understanding the relationship between domestic abuse and suicide behavior in adults receiving primary care: does forgiveness matter? Social Work; 2014; Jul; 59(4): 315-20. doi:10.1093/sw/sw/swu028

23. Laeham K. Factors affecting domestic violence risk behaviors among Thai Muslim married couples in Satun province. Kasetsart Journal of Social Sciences. 2016; 37(37): 182-89. doi.org/10.1016/j.kjss.2016.08.008

24. Lilly MM, Howell KH, Graham-Bermann S. World assumptions, religiosity, and PTSD in survivors of intimate partner violence. Violence Against Women. 2015 Jan; 21(1): 87-104. doi: 10.1177/1077801214 564139

25. Seedall RB, Butler MH, Elledge JZ. Does religious motivation influence the conceptualization and acceptability of forgiveness as a therapeutic intervention? Am J Fam Ther. 2014; 42(2): 127-40. doi: 10.1080/01926187.2013.772868

26. Band-Winterstein T, Eisikovits $Z$ and Koren C. Between remembering and forgetting: the experience of forgiveness among older abused women. Qual So Work. 2011; 10(4): 451-66. doi: $10.1177 / 1473325010361998$

27. Tsang J-A, Stanford MS. Forgiveness for intimate partner violence: the influence of victim and offender variables. Pers Individ Diff. 2007; 42(4): 653-64. doi: 10.1016/j.paid.2006.08.017

28. Kirmayer LJ. Mindfulness in cultural context. Transcult Psychiatry. 2015 Aug; 52(4): 447-69. doi: $10.1177 / 1363461515598949$

29. Goldsmith RE, Gerhart JI, Chesney SA, Burns JW, Kleinman B, Hood MM. Mindfulness-based stress reduction for posttraumatic stress symptoms: building acceptance and decreasing shame. J Evid Based Complementary Altern Med. 2014 Oct; 19(4): 227-34. doi: 10.1177/2156587214533703

30. Keng SL, Smoski MJ, Robins CJ. Effects of mindfulness on psychological health: a review of empirical studies. Clin Psychol Rev. 2011 Aug; 31(6): 1041-56. doi: 10.1016/j.cpr.2011.04.006

31. Hou WL, Ko NY, Shu BC. Recovery experiences of Taiwanese women after terminating abusive relationships: a phenomenology study. J Interpers Violence. 2013 Jan; 28(1): 157-75. doi: $10.1177 / 0886260512448851$

\section{Corresponding author}

Suwannee Sroisong can be contacted at: suwannee.bcn@gmail.com

For instructions on how to order reprints of this article, please visit our website: 